\title{
Partição da Competição Por Recursos do Solo E Radiação Solar entre Cultivares de Soja e Genótipos Concorrentes ${ }^{1}$
}

\author{
Competition Partition of Soil and Solar Radiation Resources Between Soybean Cultivars and \\ Concurrent Genotypes
}

BIANCHI, M.A. ${ }^{2}$, FLECK, N.G. ${ }^{3}$ e DILLENBURG, L.R. ${ }^{4}$

\begin{abstract}
RESUMO - As plantas competem por recursos do meio situados abaixo e/ou acima da superfície do solo. A separação física da competição entre plantas possibilita conhecer a importância relativa de cada fração, bem como apontar possíveis diferenças em competitividade entre espécies. Objetivou-se neste trabalho separar os efeitos individuais decorrentes da competição por recursos do solo ou radiação solar, entre soja e plantas concorrentes. Foram realizados seis experimentos em vasos na UFRGS, em Porto Alegre-RS, sendo dois em 2001 e quatro em 2002. Os tratamentos testados resultaram das combinações de dois genótipos concorrentes (cultura e competidor) e quatro condições de competição (ausência de competição, competição por recursos do solo e radiação solar, competição por recursos do solo e competição por radiação solar). Os cultivares de soja IAS 5 e Fepagro RS 10 representaram a cultura, enquanto o nabo forrageiro e o cultivar de soja Fundacep 33 foram os competidores. Determinaram-se variáveis morfofisiológicas em plantas de soja e de nabo forrageiro. O crescimento das plantas de soja foi mais afetado pela competição por recursos do solo, sendo o cultivar RS 10 mais competitivo do que IAS 5 . O nabo forrageiro não interferiu no crescimento dos cultivares de soja, porém cresceu mais na presença da cultura.
\end{abstract}

Palavras-chave: plantas daninhas, interferência, competitividade, raízes, Raphanus sativus.

\begin{abstract}
Plants compete for environmental resources located below and over soil surface. Physical separation of competition allows understanding the relative importance of each fraction, as well as identifying possible differences among species. The aim of this research was to separate the individual effects resulting from competition for soil or solar radiation resources, between soybean and concurrent plants. Thus, experiments using pots were carried out at UFRGS, in Porto Alegre-RS, in 2001 and 2002. The treatments tested resulted from the combinations of two concurrent genotypes (crop and competitor) and four competition conditions (absence of competition, competition for soil and solar radiation, competition for soil resources, and competition for solar radiation). Soybean cultivars IAS 5 and Fepagro RS 10 represented the crop, whereas radish forage and the soybean cultivar Fundacep 33 were the competitors tested. Morphophysiological variables were evaluated in the soybean plants and radish forage. Growth of the soybean plants was most affected by soil resources competition, with RS 10 cultivar being more competitive than IAS 5.Radish forage did not interfere in the growth of soybean cultivars but it benefited from soybean presence.
\end{abstract}

Keywords: weeds, interference, competitivity, roots, Raphanus sativus.

1 Recebido para publicação em 8.3.2006 e na forma revisada em 10.11.2006.

Parte da Tese do primeiro autor para obtenção do título de Doutor em Fitotecnia, pelo Programa de Pós-Graduação em Fitotecnia da Faculdade de Agronomia da UFRGS.

2 Pesquisador da Fundacep, Caixa Postal 10, 98100-970 Cruz Alta-RS, <mariobianchi@fundacep.com.br>; ${ }^{3}$ Professor do Dep. de Plantas de Lavoura, Faculdade de Agronomia, Universidade Federal do Rio Grande do Sul - UFRGS, Bolsista do CNPq; ${ }^{4}$ Professora do Dep. de Botânica, Instituto de Biociências - UFRGS, Bolsista do CNPq. 


\section{INTRODUÇÃO}

Espécies ou populações dentro de uma espécie que crescem próximas apresentam interações positivas e negativas. A competição é uma interação negativa, na qual os organismos envolvidos utilizam um recurso em suprimento escasso, resultando em prejuízo mútuo ao crescimento (Radosevich et al., 1997). Os recursos presentes abaixo e acima da superfície do solo, como água, nutrientes e radiação solar, são os principais envolvidos na competição em condições de campo. Há diferenças entre espécies vegetais presentes na comunidade quanto à importância relativa da competição abaixo ou acima da superfície do solo. Por exemplo, a espécie daninha Cyperus rotundus exerce maior competição por recursos encontrados abaixo da superfície do solo, devido à inabilidade desta espécie em sombrear a cultura; já Cyperus esculentus compete por recursos do solo e por radiação solar nas mesmas proporções (Morales-Payan et al., 2003).

Nos estádios iniciais de desenvolvimento da cultura, antes de ocorrer o fechamento do dossel, a competição por recursos do solo é, comparativamente, mais importante do que aquela que ocorre por radiação solar, uma vez que ainda não há limitação de radiação solar de modo a causar prejuízo ao crescimento das plantas (Semere \& Froud-Williams, 2001). No entanto, em estádios mais avançados de desenvolvimento das plantas, a competição por radiação solar é mais expressiva (Marvel et al., 1992; Fofana \& Rauber, 2000).

A competição por radiação solar induz mudanças morfológicas nas plantas, como redução da espessura foliar, emissão de afilhos e ramos, aumento do comprimento dos entre-nós (estatura de planta) e reduções na proporção de matéria seca de raízes em relação à parte aérea (Rajcan \& Swanton, 2001). Mesmo quando a quantidade de radiação solar não é limitante, como acontece nos estádios iniciais de desenvolvimento das plantas, ocorrem alterações nas plantas devido à competição (Ballaré \& Casal, 2000; Almeida \& Mundstock, 2001). Nessa situação, por causa da absorção da radiação solar vermelha pelas folhas do topo do dossel, ocorre redução na relação entre os comprimentos de onda vermelho (V) e vermelho extremo (Ve) em direção à base da planta. A radiação solar de baixa qualidade (baixa relação V:Ve) é refletida horizontalmente pelas plantas e funciona como um sinal da presença de vizinhos, desencadeando um processo de adequação da planta à competição futura (Ballaré \& Casal, 2000). Sob condições de baixa qualidade de radiação solar, há maior atividade da enzima sacarose fosfato sintase, responsável pela síntese de sacarose (Yanovsky et al., 1995), forma de transporte de carboidratos a longa distância. Desse modo, o padrão de distribuição de carboidratos é alterado antes de ocorrer redução da fotossíntese pelo sombreamento mútuo (Ballaré \& Casal, 2000).

Características da parte aérea como alto indice de área foliar, plantas altas, rápido crescimento inicial, alta capacidade de ramificação ou de afilhamento são, freqüentemente, referidas como aquelas que se relacionam com a habilidade das culturas em competir com plantas daninhas (Callaway, 1992). Em soja, por exemplo, o rápido crescimento inicial, principalmente em estatura de planta, conferiulhe maior competitividade com Brassica hirta (Jannink et al., 2000). De outro lado, poucos estudos relacionam características do sistema radicular à competitividade das culturas. Em arroz, rápido crescimento do sistema radicular associa-se com maior competitividade da cultura nos estádios iniciais de desenvolvimento; no entanto, o envolvimento da parte aérea na habilidade competitiva com plantas daninhas aumenta progressivamente com o tempo, tornando-se mais importante nos estádios mais avançados de desenvolvimento (Fofana \& Rauber, 2000). Entre espécies vegetais existem diferenças em competitividade por recursos encontrados abaixo e acima da superfície do solo, e essas diferenças, aparentemente, não se devem à maior alocação de fotoassimilados para as raízes e, conseqüentemente, mais formação de matéria seca radicular (Cahill Jr., 2003). Esse fato indica haver necessidade de separação dos papéis desempenhados pelas raízes em estudos de competição, como ancoragem da planta e absorção de água e de nutrientes.

A competição intra-específica origina maior alocação de fotoassimilados para as raízes, resultando em acréscimo na matéria seca de 
raízes e redução na produtividade, quando comparada a plantas que crescem isoladas (Gersani et al., 2001; Maina et al., 2002). Por outro lado, as plantas que crescem isoladas apresentam produtividade superior à daquelas que crescem juntas, demonstrando que, quando submetida à competição, a planta investe mais em raízes em detrimento da produtividade. Na presença de vizinhos, o sistema radicular prolifera mais em número e acumula mais matéria seca nas raízes em direção ao vizinho do que na direção de outras raízes da mesma planta. Esse processo de evitar suas próprias raízes auxilia as plantas a minimizar o desperdício na alocação de carboidratos, de modo a superar a competição com si própria (Falik et al., 2003).

Estudos de competição por recursos disponíveis abaixo e acima da superfície do solo, na sua ampla maioria, são efetuados sob condições controladas, em razão da facilidade de sua separação, do que sob condições de campo. Para estudos sob condições controladas são utilizados, basicamente, três métodos: vaso dividido, fileira de plantas e planta alvo (McPhee \& Aarssen, 2001). A técnica do vaso dividido consiste na partição do espaço acima e abaixo da superfície do solo em forma de "+", em que uma divisória separa a competição abaixo da superfície do solo e a outra aquela que ocorre acima da superfície. O método da fileira de plantas consiste em arranjar as plantas em linhas paralelas, sendo a competição determinada pela presença de partição entre as fileiras. Por último, na técnica da planta alvo os competidores cercam a planta objeto do estudo; nesse caso, a divisória isola os efeitos desejados somente para a plantaalvo. Nos três métodos são geradas quatro situações de competição: ausência de competição, competição apenas por recursos do solo, somente por radiação solar e por ambas as fontes de recursos (competição total).

$\mathrm{Na}$ escolha da técnica devem ser consideradas suas limitações (McPhee \& Aarssen, 2001). O método do vaso dividido e o da fileira de plantas separam a competição entre genótipos ou espécies vegetais; no entanto, dentro da espécie ou genótipo ocorre competição total. Outro inconveniente na técnica da fileira de plantas é que, se as divisórias forem transparentes, não impedem a competição por radiação solar, e, se forem opacas, causam sombreamento excessivo às plantas; além disso, as divisórias podem criar microclima diferente daquele do ambiente externo. O método da planta alvo, embora seja o que mais se aproxima da condição natural de competição entre plantas, apresenta a desvantagem de não incluir as partições necessárias para simular as situações de competição em todos os tratamentos, podendo o efeito da competição ser confundido com o das partições (McPhee \& Aarssen, 2001). Mesmo assim, a utilização das técnicas descritas anteriormente permite separar adequadamente a competição que ocorre abaixo e acima da superfície do solo, indicando qual fração confere maior competitividade às plantas.

Objetivou-se com este trabalho separar os efeitos individuais decorrentes da competição por recursos do solo ou da radiação solar, entre soja e plantas concorrentes.

\section{MATERIAL E MÉTODOS}

Foram realizados seis experimentos em ambiente de telado, na Faculdade de Agronomia da UFRGS, em Porto Alegre-RS. De dezembro de 2001 a janeiro de 2002 foram conduzidos os ensaios 1 e 2 , e de outubro de 2002 a janeiro de 2003, os ensaios 3 a 6 . Para estudar a competição que ocorre acima e abaixo da superfície do solo foi utilizado o método da fileira de plantas, referido por McPhee \& Aarssen (2001), com modificações, visando minimizar as limitações do método. Os tratamentos foram individualizados em recipientes plásticos sem colocação de divisórias laterais, efetuando-se diariamente a rotação dos vasos para diminuir a influência do sombreamento causado pela divisória. Os genótipos avaliados foram arranjados em fileiras paralelas, sendo o recurso pelo qual as plantas competiam determinado pelo tipo de partição que separava as fileiras. Os tratamentos testados resultaram das combinações de dois genótipos concorrentes (cultura e competidor) e quatro condições de competição [ausência de competição entre genótipos (Nula) e competição por recursos do solo + radiação solar (Total), somente por recursos do solo (Solo) e apenas por radiação solar (Luz)]. Os cultivares de soja IAS 5 e Fepagro RS 10 (RS 10) representaram a cultura, enquanto Raphanus sativus 
(nabo forrageiro) e o cultivar de soja Fundacep 33 foram selecionados como competidores.

No ensaio 1, foi avaliada a competição entre IAS 5 e Fundacep 33; no ensaio 2, entre RS 10 e Fundacep 33; no ensaio 3, IAS 5 e Fundacep 33; no ensaio 4, RS 10 e Fundacep 33; no ensaio 5, IAS 5 e nabo; e, no ensaio 6, RS 10 e nabo. Foi utilizado o esquema fatorial $2 \times 4$, com os tratamentos dispostos no delineamento experimental inteiramente ao acaso, com quatro repetições. Nos ensaios 1 e 2 , as unidades experimentais foram formadas por vasos plásticos com $0,24 \mathrm{~m}$ de diâmetro e $0,26 \mathrm{~m}$ de altura (área $=0,0452 \mathrm{~m}^{2}$ e volume $=0,0117 \mathrm{~m}^{3}$ ). Nos ensaios 3 a 6 , as unidades experimentais foram constituídas por caixas plásticas com $0,30 \times 0,38 \mathrm{~m}$ de superfície e $0,26 \mathrm{~m}$ de altura (área $=0,114 \mathrm{~m}^{2}$ e volume $=$ $0,0296 \mathrm{~m}^{3}$ ). Os recipientes plásticos foram preenchidos com solo de textura arenosa, cujas características físico-químicas foram as seguintes: argila: 23\%; matéria orgânica: 2,6\%; pH em água: 5,5; fósforo: $40 \mathrm{mg} \mathrm{L}^{-1}$; potássio: $140 \mathrm{mg} \mathrm{L}^{-1}$; alumínio: zero; e saturação de bases: $60 \%$. As sementes foram posicionadas a $3 \mathrm{~cm}$ de profundidade para soja e a $0,5 \mathrm{~cm}$ para nabo. Dez dias após a semeadura foi efetuado desbaste do excesso de plântulas, permanecendo as mais vigorosas em cada unidade experimental. O solo foi mantido com umidade próxima da capacidade de campo por meio de irrigações.

Os genótipos concorrentes, cultura e competidor, foram alocados em fileiras paralelas (Figura 1a), com três plantas por fileira nos vasos e quatro plantas por fileira nas caixas, totalizando seis plantas por vaso (133 plantas $\mathrm{m}^{-2}$ ) e oito plantas por caixa (70 plantas $\mathrm{m}^{-2}$ ). Para separar fisicamente as fileiras de plantas foram colocadas divisórias (Figura 1b). Para isolar a competição na parte aérea foram utilizadas divisórias de madeira revestidas por filme de alumínio. A fim de evitar a competição por recursos do solo entre genótipos diferentes (tratamento Luz), o solo correspondente a cada metade da caixa ou vaso foi colocado em sacos plásticos, separadamente. Na testemunha, plantas da cultura e do competidor cresceram juntas, porém separadas por divisórias acima e abaixo da superfície do solo. O revestimento das divisórias com filme de alumínio visou refletir a radiação solar (a)

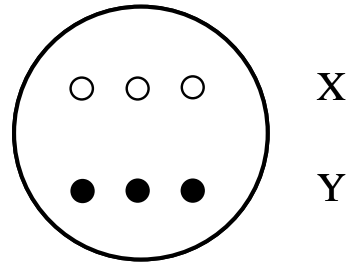

Vaso

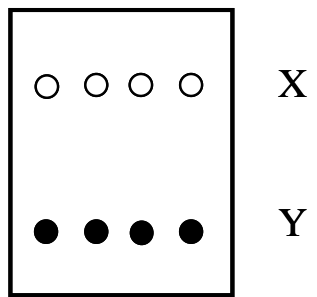

Caixa

(b)

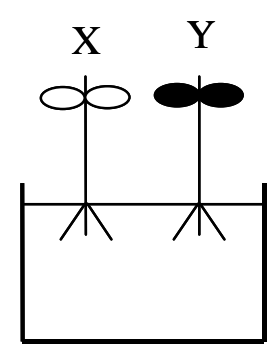

Total

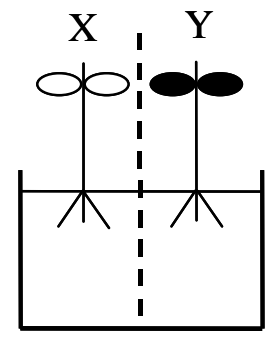

Nula

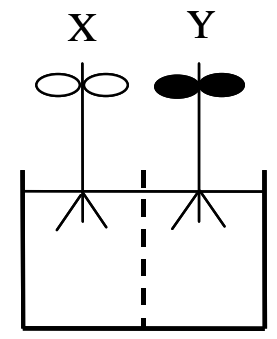

Luz

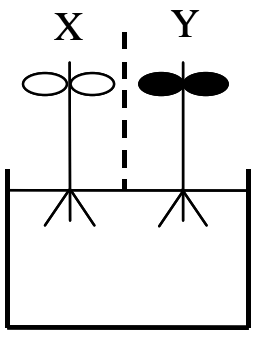

Solo

Figura 1 - Esquema de distribuição das plantas em vasos e caixas plásticas (a) e posicionamento da divisória (linha tracejada) nos tratamentos estudados (b). A letra "X" representa a fileira de plantas da cultura, e a letra "Y", a do genótipo competidor. 
e, desse modo, camuflar sua presença para as plantas. De acordo com o crescimento das plantas, os vasos e as caixas plásticos eram afastados o suficiente para prevenir a interferência entre plantas de unidades experimentais diferentes.

Aos 41 dias após a emergência das plantas de soja, foram determinados estatura de planta, estádio fenológico, área foliar (AF), massa da matéria seca foliar e da parte aérea (MPA) dos cultivares de soja (IAS 5, RS 10 e Fundacep 33) e a MPA do nabo forrageiro. A estatura foi obtida pela mensuração da distância da base até o ponto de crescimento na extremidade do caule. O estádio fenológico foi determinado através da contagem do número de nós, considerando-se como primeiro nó aquele correspondente ao par de folhas unifolioladas (Costa \& Marchezan, 1982). A área foliar foi medida na fração folhas (folíolos sem pecíolos), em aparelho modelo Area Meter 3100. A massa da matéria seca foliar (foliolos sem pecíolos) e da parte aérea foi obtida pela pesagem das partes, após secagem em estufa a $65{ }^{\circ} \mathrm{C}$ por três dias.

As variáveis razão de massa foliar (RMF), área foliar específica (AFE) e razão de área foliar (RAF) foram calculadas através das seguintes equações citadas em Radosevich et al. (1997): $\mathrm{RMF}=\mathrm{MF} / \mathrm{MPA} ; \mathrm{AFE}=\mathrm{AF} / \mathrm{MF} ; \mathrm{e} \mathrm{RAF}=\mathrm{AF} /$ MPA, em que MF = massa da matéria seca foliar, MPA = massa da matéria seca da parte aérea e $\mathrm{AF}$ = área foliar. A utilização dessas variáveis visou indicar a alocação de fotoassimilados através da proporção de folhas (RMF e RAF) e da expansão foliar (AFE).

Inicialmente, os dados foram submetidos à análise de variância, verificando-se, previamente, sua homogeneidade através de análise gráfica dos resíduos versus valores preditos. Quando o teste $\mathrm{F}$ da análise de variância indicou significância (efeito principal p d 0,05; interação p d 0,15), as médias foram comparadas pelo teste da DMS $(p=0,05)$. A análise estatística dos dados foi feita por meio do programa computacional SAS (SAS, 1989).

\section{RESULTADOS E DISCUSSÃO}

O efeito da competição mútua entre genótipos foi mais pronunciado na combinação dos cultivares IAS 5 com Fundacep 33 (ensaio 1) do que na combinação de RS 10 com Fundacep 33 (ensaio 2) (Tabela 1 e Figura 2). No ensaio 1, independentemente da sua natureza, a competição por recursos do ambiente reduziu o número de nós emitidos pelas plantas de soja. Ainda, tanto a competição total como por radiação solar reduziram a estatura das plantas de soja; contudo, a área foliar não foi alterada pela natureza da competição. No ensaio 2, não ocorreram diferenças para as variáveis estádio fenológico, estatura de planta e área foliar quanto à natureza da competição. No entanto, a natureza da competição alterou a MPA no ensaio 1 (Figura 2a), mas não alterou essa variável no ensaio 2 (Figura 2b). No ensaio 1, a MPA do cultivar IAS 5 não foi alterada sob competição; já o cultivar competidor Fundacep 33 teve sua MPA reduzida quando competiu pelo recurso radiação solar e, também, quando a competição foi total (Figura 2a).

Tabela 1 - Estádio fenológico (nós), estatura (cm) e área foliar ( $\mathrm{cm}^{2}$ por planta) de plantas de cultivares de soja em competição por recursos do ambiente, avaliados aos 41 dias após a emergência - UFRGS, Porto Alegre-RS, 2001

\begin{tabular}{|c|c|c|c|}
\hline $\begin{array}{c}\text { Natureza da } \\
\text { competição/ } \\
\text { Cultivares } \\
\text { concorrentes }\end{array}$ & $\begin{array}{l}\text { Estádio } \\
\text { fenológico }\end{array}$ & $\begin{array}{l}\text { Estatura de } \\
\text { planta }\end{array}$ & Área foliar \\
\hline & \multicolumn{3}{|c|}{ Ensaio 1: IAS 5 x Fundacep 33} \\
\hline \multicolumn{4}{|l|}{ Competição } \\
\hline Nula & " 7,8 a ${ }^{\prime \prime}$ & 30,3 a & 470 ns' \\
\hline Total & " 7,3 b & $26,8 \mathrm{c}$ & 397 \\
\hline Solo & $7,4 \mathrm{~b}$ & $29,4 a b$ & 394 \\
\hline Luz & $7,3 \mathrm{~b}$ & $27,6 \mathrm{bc}$ & 420 \\
\hline \multicolumn{4}{|l|}{ Cultivares } \\
\hline IAS 5 & " 7,8 A & $25,1 \mathrm{~B}$ & 431 ns" \\
\hline Fundacep 33 & $7,1 \mathrm{~B}$ & $31,9 \mathrm{~A}$ & 410 \\
\hline \multirow[t]{2}{*}{$\mathrm{CV}(\%)$} & 5,3 & 7,3 & 15,7 \\
\hline & \multicolumn{3}{|c|}{ Ensaio 2: RS 10 x Fundacep 33} \\
\hline \multicolumn{4}{|l|}{ Competição } \\
\hline Nula & "'t"' 7,1 ns' & 31,3 ns & $414^{\text {ns' }}$ \\
\hline Total & 7,7 & 30,0 & 374 \\
\hline 'solo & " 7,8 & 31,2 & 421 \\
\hline Luz & 7,7 & 30,5 & 456 \\
\hline \multicolumn{4}{|l|}{ Cultivares } \\
\hline Fepagro RS 10 & $8,0 \mathrm{~A}$ & $27,5 \mathrm{~B}$ & $445 \mathrm{~A}$ \\
\hline Fundacep 33 & $7,1 \mathrm{~B}$ & $34,0 \mathrm{~A}$ & $387 \mathrm{~B}$ \\
\hline $\mathrm{CV}(\%)$ & 8,4 & 11,2 & 18,4 \\
\hline
\end{tabular}

1/ Médias seguidas pela mesma letra minúscula (competição) ou maiúscula (cultivares), comparadas nas colunas, não diferem significativamente pelo teste da DMS a $5 \%$ de probabilidade do erro.

ns Teste $\mathrm{F}$ da análise de variância não-significativo a $5 \%$ de probabilidade do erro. 

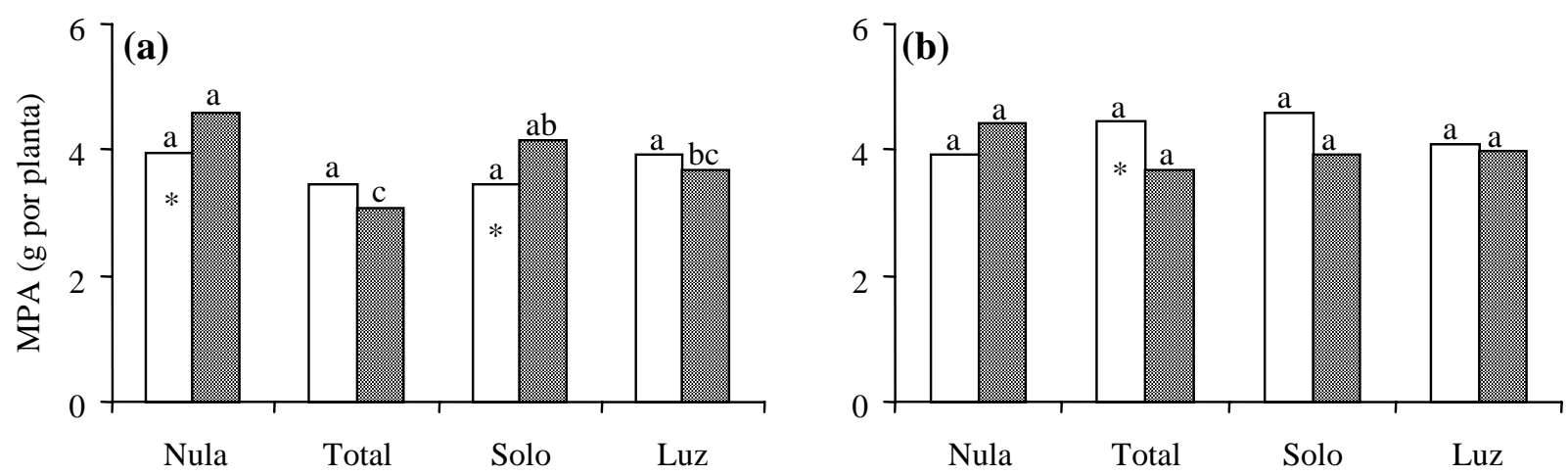

Figura 2 - Matéria seca da parte aérea (MPA) de plantas de cultivares de soja em competição por recursos do ambiente, avaliada aos 41 dias após a emergência - UFRGS, Porto Alegre-RS, 2001. a) ensaio 1: cultivares IAS 5 (colunas claras) e Fundacep 33 (colunas escuras); b) ensaio 2: cultivares Fepagro RS 10 (colunas claras) e Fundacep 33 (colunas escuras). Natureza da competição: recursos do solo + radiação solar (Total), radiação solar (Luz), recursos do solo (Solo) e ausência de competição (Nula). Colunas de mesma textura não diferem entre si quando sobrescritas com a mesma letra; para colunas de texturas diferentes, * indica diferença significativa; em ambos os casos, os valores foram testados pela DMS a 5\% de probabilidade do erro.

Os cultivares de soja se caracterizaram por diferenças no crescimento de plantas (Tabela 1 e Figura 2). No ensaio 1, o cultivar IAS 5 apresentou estádio fenológico mais avançado, menor estatura de planta e área foliar similar à do genótipo competidor Fundacep 33. Este cultivar produziu mais MPA que o IAS 5 na ausência de competição e quando ela se deu por recursos do solo (Figura 2a). Entretanto, competindo apenas pelo recurso radiação solar ou sob competição total, a MPA de Fundacep 33 foi equivalente à de IAS 5. No ensaio 2, RS 10 apresentou estádio fenológico mais avançado, menor estatura de planta e maior área foliar que a do genótipo Fundacep 33. O cultivar RS 10 superou Fundacep 33 em MPA somente sob competição total (Figura 2b).

Os resultados dos ensaios 1 e 2 demonstram, de modo geral, que a competição por radiação solar teve maior participação nas relações de interferência de IAS 5 com Fundacep 33 (alcançou menor AF que IAS 5), sendo este último mais sensível à competição; já entre os genótipos RS 10 e Fundacep 33 não se verificou influência da natureza da competição nas relações de interferência. Isso significa que RS 10 e Fundacep 33 se complementam melhor no "espaço" (utilização de recursos), enquanto plantas de IAS 5 e Fundacep 33 tendem a ocupar o mesmo nicho ecológico. A magnitude do sombreamento da espécie daninha sobre a cultura determina o grau de importância da radiação solar nas relações de competição (Morales-Payan et al., 2003).

Nos ensaios 3 e 4, por outro lado, a maior proporção da interferência total deveu-se, geralmente, à competição por recursos do solo. Nesses experimentos, a competição por todos os recursos disponiveis reduziu o número de nós, a estatura e a área foliar das plantas de soja (Tabela 2). Adicionalmente, a competição por recursos do solo diminuiu a estatura e a área foliar das plantas de soja. A competição por recursos do solo foi a principal responsável por essa redução, já que, quando as plantas competiram por radiação solar, em geral essas variáveis não foram alteradas, quando comparadas à ausência de competição. De modo relativamente semelhante aos efeitos encontrados nos ensaios 1 e 2, o cultivar Fundacep 33 apresentou maior estatura de planta e menor área foliar do que IAS 5 e RS 10, enquanto seu estádio fenológico ficou aquém daquele de RS 10.

A competição total reduziu a MPA média das plantas de soja dos cultivares IAS 5 e Fundacep 33 no ensaio 3 (Figura 3a). A competição que ocorreu abaixo da superfície do solo reduziu relativamente mais a MPA que aquela que ocorreu acima da superfície. No ensaio 4, em que foram avaliados os cultivares RS 10 e Fundacep 33, a MPA diminuiu em ambos 
Tabela 2 - Estádio fenológico (nós), estatura (cm) e área foliar $\left(\mathrm{cm}^{2}\right.$ por planta) de plantas de cultivares de soja em competição por recursos do ambiente, avaliados aos 41 dias após a emergência - UFRGS, Porto Alegre-RS, 2002

\begin{tabular}{|c|c|c|c|}
\hline $\begin{array}{c}\text { Natureza da } \\
\text { competição/ } \\
\text { Cultivares } \\
\text { concorrentes }\end{array}$ & $\begin{array}{l}\text { Estádio } \\
\text { fenológico }\end{array}$ & $\begin{array}{l}\text { Estatura de } \\
\text { planta }\end{array}$ & Área foliar \\
\hline & \multicolumn{3}{|c|}{ Ensaio 3: IAS $5 \times$ Fundacep 33} \\
\hline \multicolumn{4}{|l|}{ Competição } \\
\hline Nula & $8,4 \mathrm{ab}^{1 /{ }^{1 / 2}}$ & $41,0 \mathrm{a}$ & $634,0 \mathrm{a}$ \\
\hline Total & $7,9 \mathrm{c}$ & $34,8 \mathrm{c}$ & $500,0 \mathrm{~b}$ \\
\hline Solo & $8,0 \mathrm{bc}$ & $35,8 \mathrm{bc}$ & $539,0 \mathrm{~b}$ \\
\hline Luz & 8,8 a & $38,6 \mathrm{ab}$ & 608,0 a \\
\hline \multicolumn{4}{|l|}{ Cultivares } \\
\hline IAS 5 & 8,4 ns & $34,0 \mathrm{~B}$ & $617,0 \mathrm{~A}$ \\
\hline Fundacep 33 & 8,2 & $41,1 \mathrm{~A}$ & $523,4 \mathrm{~B}$ \\
\hline \multirow[t]{2}{*}{$\mathrm{CV}(\%)$} & 6,3 & 8,0 & 11,1 \\
\hline & \multicolumn{3}{|c|}{ Ensaio 2: RS 10 x Fundacep 33} \\
\hline \multicolumn{4}{|l|}{ Competição } \\
\hline Nula & $8,3 \mathrm{a}$ & $42,5 \mathrm{a}$ & $607,0 \mathrm{a}$ \\
\hline Total & $7,6 \mathrm{~b}$ & $31,7 \mathrm{c}$ & $449,0 \mathrm{c}$ \\
\hline Solo & $8,3 \mathrm{a}$ & $36,7 \mathrm{~b}$ & $529,0 \mathrm{~b}$ \\
\hline Luz & $8,7 \mathrm{a}$ & $38,9 \mathrm{~b}$ & $621,1 \mathrm{a}$ \\
\hline \multicolumn{4}{|l|}{ Cultivares } \\
\hline Fepagro RS 10 & $8,4 \mathrm{~A}$ & $35,4 \mathrm{~B}$ & 629,0 A \\
\hline Fundacep 33 & $8,0 \mathrm{~B}$ & $39,5 \mathrm{~A}$ & $474,0 \mathrm{~B}$ \\
\hline $\mathrm{CV}(\%)$ & 6,0 & 6,8 & 13,4 \\
\hline
\end{tabular}

1/ Médias seguidas pela mesma letra minúscula (competição) ou maiúscula (cultivares), comparadas nas colunas, não diferem significativamente pelo teste da DMS a 5\% de probabilidade do erro.

${ }^{\text {ns }}$ Teste $\mathrm{F}$ da análise de variância não-significativo a $5 \%$ de probabilidade do erro. quando as plantas foram submetidas à competição total (Figura 3b). Já a competição por recursos do solo causou redução da MPA em RS 10. Para Fundacep 33, a competição por recursos encontrados abaixo da superfície do solo foi mais severa do que pelo recurso radiação solar.

O cultivar RS 10 só não produziu mais MPA que o genótipo Fundacep 33 quando a competição se deu exclusivamente por radiação solar. Para ambos os cultivares, a competição que ocorreu por recursos disponiveis abaixo da superfície do solo contribuiu em maior proporção para reduzir a MPA. Por outro lado, competindo somente por radiação solar, Fundacep 33 conseguiu produzir MPA similar à de RS 10, indicando elevada habilidade daquele cultivar em competir por radiação solar, o que pode ser atribuído, em parte, à sua maior estatura de planta. Em plantas de milho e ervilha, por exemplo, as características estatura de planta, área foliar e MPA foram reduzidas quando ocorreu competição por recursos do solo, ao passo que a competição por radiação solar não teve efeito sobre esses atributos (Semere \& Froud-Williams, 2001), indicando, nesse caso, que recursos disponiveis abaixo da superfície do solo são mais importantes nas relações de competição do que a radiação solar, ao menos durante a fase de crescimento vegetativo das plantas.
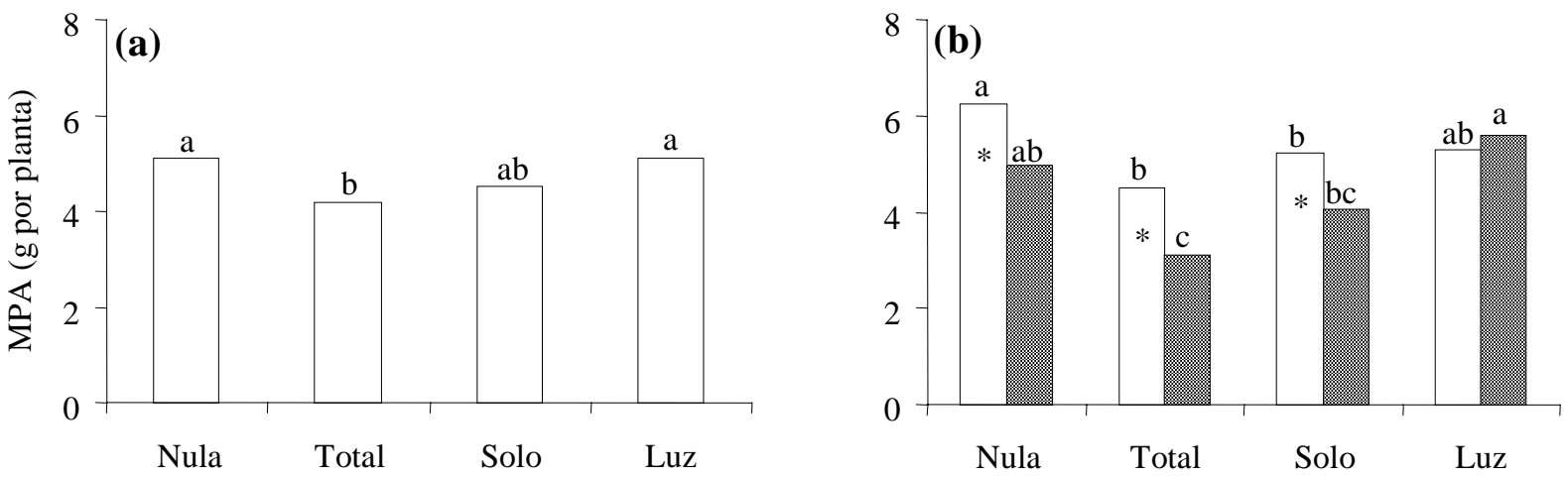

Figura 3 - Matéria seca da parte aérea (MPA) de plantas de cultivares de soja em competição por recursos do ambiente, avaliada aos 41 dias após a emergência - UFRGS, Porto Alegre-RS, 2002. a) ensaio 3: médias dos cultivares IAS 5 e Fundacep 33; b) ensaio 4: cultivares Fepagro RS 10 (colunas claras) e Fundacep 33 (colunas escuras). Natureza da competição: recursos do solo + radiação solar (Total), radiação solar (Luz), recursos do solo (Solo) e ausência de competição (Nula). Colunas de mesma textura não diferem entre si quando sobrescritas com a mesma letra; para colunas de texturas diferentes, * indica diferença significativa; em ambos os casos, os valores foram testados pela DMS a 5\% de probabilidade do erro. 
Quando as plantas de soja sofreram competição por recursos do ambiente, a RMF diminuiu tanto no experimento onde cresceram juntos IAS 5 e Fundacep 33 (ensaio 3) como naquele em que cresceram RS 10 e Fundacep 33 (ensaio 4) (Tabela 3). Provavelmente, os fotoassimilados foram redirecionados na parte aérea das plantas para outros órgãos que não as folhas (por exemplo, pecíolos, ramos e caule). Entre os cultivares estudados, Fundacep 33 apresentou menor RMF.

No ensaio 3, a natureza da competição não alterou as variáveis AFE e RAF; contudo, o cultivar IAS 5 apresentou maior AFE (maior expansão foliar por unidade de massa) e plantas mais folhosas (maior RAF) do que Fundacep 33 (Tabela 3). No ensaio 4, a competição por recursos do ambiente aumentou a AFE e a RAF de RS 10, mas não alterou essas variáveis em Fundacep 33 (Figura 4). O genótipo Fundacep 33, ao manter inalteradas AFE e RAF, demonstra ter habilidade em conservar esses atributos fisiológicos sob competição, o que não se observa no cultivar RS 10 sob competição, caracterizando a maior plasticidade funcional deste último. O sombreamento faz com que as folhas se expandam mais por unidade de massa (folhas maiores), porém, conseqüentemente, elas ficam mais finas (Dias Filho, 2000; Radin et al., 2004).
Pelo exposto, o cultivar RS 10 reagiu à competição pelos recursos do solo, reduzindo a expansão foliar (menor AFE) e aumentando a RAF. Na comparação entre cultivares, RS 10 apresentou maior AFE do que Fundacep 33 quando submetido à competição (Figura 4a) e manteve maior RAF que Fundacep 33 em todas as condições de competição impostas (Figura 4b). Em experimentos de curta duração, com suprimento homogêneo de recursos, as plantas alocam maior proporção de fotoassimilados para os órgãos responsáveis pela aquisição de recursos que estão limitados no ambiente (Shipley \& Meziane, 2002). Por outro lado, em condições de campo e por período de tempo mais longo, a disponibilidade de recursos do ambiente costuma ser temporalmente heterogênea, não se verificando alocação diferenciada de carboidratos entre raízes e parte aérea das plantas (Cahill Jr., 2003). Para algumas combinações de plantas (arroz irrigado e Echinochloa phyllopogon, por exemplo), a competição por recursos localizados abaixo da superfície do solo representa o mecanismo principal responsável pela redução de produtividade da cultura (Gibson et al., 1999). Supõe-se que genótipos que apresentam maior flexibilidade na alocação de fotoassimilados para as raízes no período inicial de crescimento constituam-se, potencialmente, em fortes competidores em fases mais adiantadas do desenvolvimento da planta.

Tabela 3 - Razão de massa foliar (RMF - g de folha por g de planta), área foliar específica (AFE - $\mathrm{cm}^{2}$ de folha por $\mathrm{g}$ de folha) e razão de área foliar (RAF $-\mathrm{cm}^{2}$ de folha por $\mathrm{g}$ de planta) de plantas de cultivares de soja em competição por recursos do ambiente - UFRGS, Porto Alegre-RS, 2002

\begin{tabular}{|c|c|c|c|c|}
\hline \multirow{2}{*}{$\begin{array}{l}\text { Natureza da competição/ } \\
\text { Cultivares concorrentes }\end{array}$} & RMF & AFE & RAF & \multirow{2}{*}{$\begin{array}{c}\text { RMF } \\
\text { Ensaio } 4 \text { (RS 10 x Fundacep 33) }\end{array}$} \\
\hline & \multicolumn{3}{|c|}{ Ensaio 3 (IAS 5 x Fundacep 33) } & \\
\hline \multicolumn{5}{|l|}{ Competição } \\
\hline Nula & $0,46 \mathrm{a}^{\mathbf{1}{ }^{\prime \prime}}$ & $228^{\text {ns }}$ & $105^{\mathrm{ns}}$ & $0,46 \mathrm{a}$ \\
\hline Total & $0,44 \mathrm{~b}$ & 231 & 103 & $0,44 \mathrm{~b}$ \\
\hline Solo & $0,44 \mathrm{~b}$ & 227 & 102 & $0,44 \mathrm{~b}$ \\
\hline Luz & $0,45 \mathrm{ab}$ & 222 & 100 & $0,44 \mathrm{~b}$ \\
\hline \multicolumn{5}{|l|}{ Cultivares } \\
\hline IAS 5 ou Fepagro RS 10 & $0,52 \mathrm{~A}$ & $247 \mathrm{~A}$ & $128 \mathrm{~A}$ & $0,51 \mathrm{~A}$ \\
\hline Fundacep 33 & $0,38 \mathrm{~B}$ & $207 \mathrm{~B}$ & $78 \mathrm{~B}$ & $0,39 \mathrm{~B}$ \\
\hline $\mathrm{CV}(\%)$ & 2,80 & 7,6 & 6,5 & 3,50 \\
\hline
\end{tabular}

${ }^{1 /}$ Médias seguidas pela mesma letra minúscula (competição) ou maiúscula (cultivares), comparadas nas colunas, não diferem significativamente pelo teste da DMS a 5\% de probabilidade do erro.

${ }^{n s}$ Teste $\mathrm{F}$ da análise de variância não-significativo a 5\% de probabilidade do erro. 

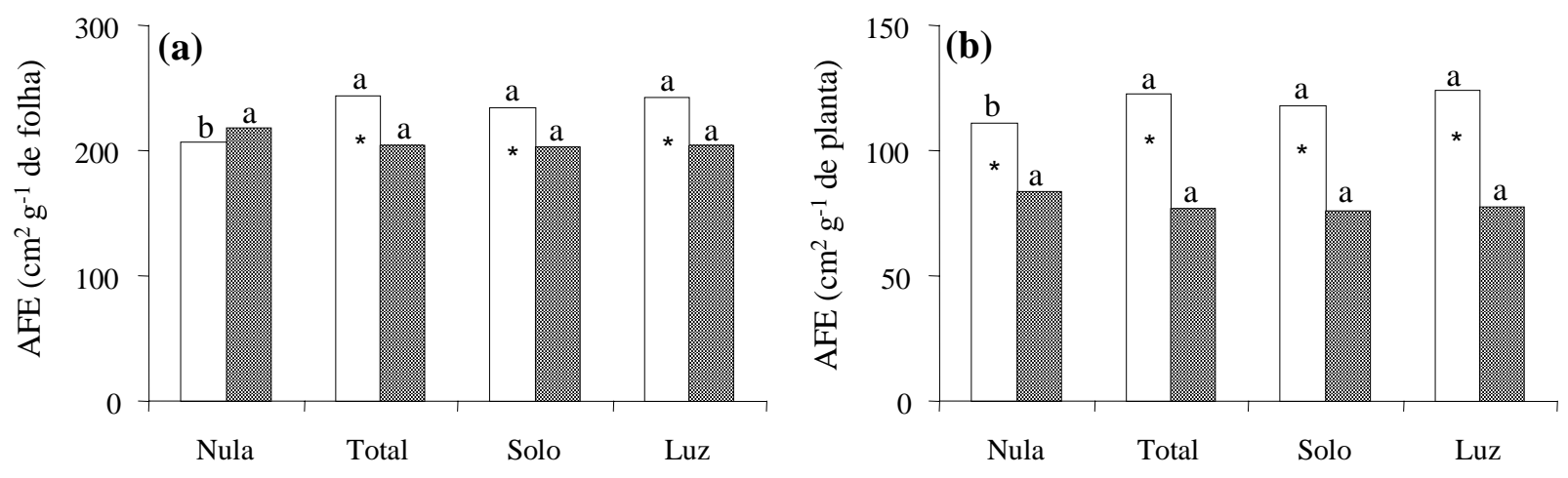

Figura 4 - Área foliar específica (AFE) em “(a)” e razão de área foliar (RAF) em “(b)” de plantas de cultivares de soja em competição por recursos do ambiente no ensaio 4, avaliadas aos 41 dias após a emergência - UFRGS, Porto Alegre-RS, 2002. Cultivares Fepagro RS 10 (colunas claras) e Fundacep 33 (colunas escuras). Natureza da competição: recursos do solo + radiação solar (Total), radiação solar (Luz), recursos do solo (Solo) e ausência de competição (Nula). Colunas de mesma textura não diferem entre si quando sobrescritas com a mesma letra; para colunas de texturas diferentes, * indica diferença significativa; em ambos os casos, os valores foram testados pela DMS a $5 \%$ de probabilidade do erro.

A alteração da qualidade da radiação solar causa modificações morfofisiológicas em plantas, como aumento da área foliar específica, antes de ocorrer redução na radiação fotossinteticamente ativa (Ballaré \& Casal, 2000). Desse modo, mesmo não tendo ocorrido competição por quantidade de radiação solar, a alteração na distribuição do carbono fixado pode decorrer da qualidade da radiação solar refletida pelo dossel.

No ensaio 1, a radiação solar contribuiu mais para o resultado da competição total; já nos ensaios 3 e 4 a competição por recursos do solo revelou ser mais importante. A disputa mais intensa pelos recursos do solo entre sistemas radicais dos cultivares de soja pode ter resultado em fluxo preferencial de fotoassimilados para as raízes. Plantas direcionam maior proporção de carboidratos para raízes em ambientes com baixa disponibilidade de água e nutrientes (Liu \& Stützel, 2004) e priorizam mais carboidratos para a parte aérea quando ocorre limitação de radiação solar (Dias Filho, 2000). Assim, o cultivar de soja que alocou maior quantidade de substâncias para as raízes e ainda conseguiu manter nível satisfatório de crescimento da parte aérea tornou-se mais competitivo, como é o caso do cultivar RS 10. Esse cultivar direcionou maior proporção de carboidratos para estruturas que não as folhas (menor RMF), formou folhas mais amplas e delgadas (maior AFE) e desenvolveu maior RAF. Tais compensações permitem inferir que tenha ocorrido realocação de fotoassimilados na planta e, mesmo não tendo sido determinado o crescimento de raízes, possivelmente parte desses compostos foi canalizado para estas, conferindo ao cultivar maior capacidade competitiva.

A massa da matéria seca da parte aérea dos cultivares de soja IAS 5 e RS 10 não foi alterada pela natureza da competição com nabo forrageiro (Figura 5). No entanto, o nabo forrageiro cresceu mais na presença de plantas de soja, principalmente quando não foi interposta barreira no solo, ou seja, quando a competição se deu por recursos do solo ou foi total. As diferenças em crescimento do nabo forrageiro indicam que há resposta dessa espécie ao volume de solo explorado, já que na ausência de competição, ou competindo por radiação solar, o volume de solo disponível para o crescimento radicular representava a metade daquele disponível na competição total ou por recursos do solo. Considerando-se que o solo das unidades experimentais recebia água com freqüência, é provável que o nabo forrageiro tenha explorado principalmente os nutrientes aí disponíveis, sendo muito responsivo a eles.

O benefício referido anteriormente pode estar associado, mais especificamente, ao nitrogênio (N) do solo, pois esse nutriente estaria disponível em maior quantidade para 


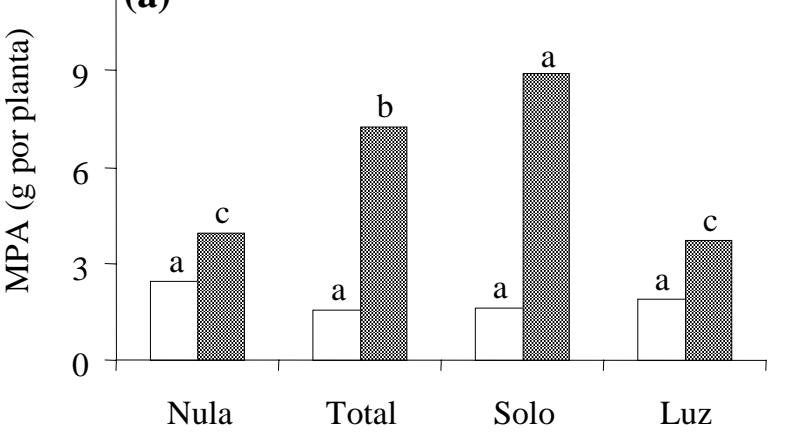

12

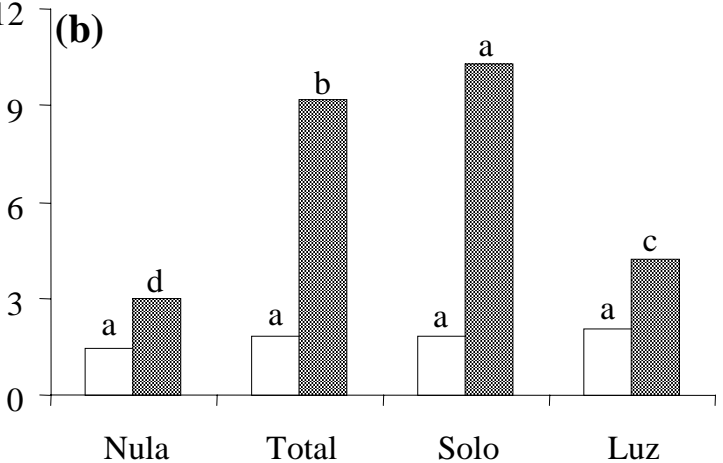

Figura 5 - Matéria seca da parte aérea (MPA) de plantas de cultivares de soja e de nabo forrageiro em competição por recursos do ambiente, avaliada aos 41 dias após a emergência - UFRGS, Porto Alegre-RS, 2002. a) ensaio 5: cultivar IAS 5 (colunas claras) e nabo forrageiro (colunas escuras); b) ensaio 6: cultivar Fepagro RS 10 (colunas claras) e nabo forrageiro (colunas escuras). Natureza da competição: recursos do solo + radiação solar (Total), radiação solar (Luz), recursos do solo (Solo) e ausência de competição (Nula). Os valores de mesma textura não diferem entre si quando sobrescritas com a mesma letra pelo teste da DMS a $5 \%$ de probabilidade do erro.

ser absorvido nos tratamentos em que havia maior volume de solo a ser explorado pelas raízes. A soja absorve $\mathrm{N}$ principalmente por intermédio da simbiose com bactérias fixadoras de $\mathrm{N}_{2}$ do ar, não competindo diretamente com nabo forrageiro por N. Desse modo, maior quantidade de $\mathrm{N}$ fica disponível no solo para o crescimento do nabo forrageiro, sem afetar o crescimento da soja. Comportamento semelhante foi verificado com a espécie daninha Solanum ptycanthum. Essa espécie cresceu mais na presença de soja do que em monocultura, devido à disponibilidade de $\mathrm{N}$ ser mais elevada na presença da cultura (Crotser \& Witt, 2000). O nabo forrageiro, por sua vez, evitou a competição direta com soja porque cresceu mais que a cultura, demonstrando explorar nicho ecológico diferenciado. Por outro lado, o alto grau de afinidade entre genótipos de soja indica que estes possuem requisitos de nicho semelhantes, resultando em competição mais intensa pelos recursos do ambiente (Radosevich et al., 1997).

As modificações em atributos morfofisiológicos entre plantas concorrentes, ocorridas neste trabalho, demonstram que as plantas respondem rápida e diferentemente à competição pelos recursos do ambiente. Nota-se, também, que o mesmo genótipo pode reagir de forma diferente à competição por recursos presentes abaixo ou acima da superfície do solo, conforme as características de crescimento de plantas vizinhas. A competição por recursos do solo e radiação solar não é independente, e tanto o sistema radicular como a parte aérea das plantas efetuam trocas rápidas no que se refere à alocação de fotoassimilados, quando uma ou outra fração é mais exigida para enfrentar a competição (Cahill Jr., 2002). Dessa forma, dependendo da fase de desenvolvimento da planta e da intensidade da competição, pode ocorrer alternância na importância relativa da competição por recursos situados abaixo e acima da superfície do solo. Contudo, a competição que ocorre nas fases iniciais de desenvolvimento por recursos do solo (Semere \& Froud-Williams, 2001) e a modulação do crescimento devido à qualidade de radiação solar (Ballaré \& Casal, 2000; Almeida \& Mundstock, 2001) definem o padrão de crescimento futuro de uma planta em relação aos seus vizinhos.

Os resultados evidenciaram que durante o período de crescimento vegetativo da soja a competição por recursos do solo predomina sobre a competição por radiação solar, resultando em redução da estatura de planta, da área foliar, da matéria seca da parte aérea e da razão de massa foliar, bem como em aumento da área foliar específica e da razão de área foliar da soja. Além disso, os cultivares de soja apresentam diferenças em suas habilidades em 
utilizar os recursos do meio, sendo o cultivar Fepagro RS 10 mais competitivo por recursos do solo do que o IAS 5. O nabo forrageiro não interfere no crescimento dos cultivares IAS 5 e RS 10, mas obtém benefício de crescimento quando suas raízes e as de soja compartilham o mesmo ambiente.

\section{LITERATURA CITADA}

ALMEIDA, M. L.; MUNDSTOCK, C. M. A qualidade da luz afeta o afilhamento em plantas de trigo quando cultivadas sob competição. Ci. Rural, v. 31, p. 401-408, 2001.

BALLARÉ, C. L.; CASAL, J. J. Light signals perceived by crop and weed plants. Field Crops Res., v. 67, p. 149-160, 2000.

CAHILL Jr., J. F. Interactions between root and shoot competition vary among species. Oikos, v. 99, p. 101-112, 2002.

CAHILL Jr., J. F. Lack of relationship between below-ground competition and allocation to roots in 10 grassland species. J. Appl. Ecol., v. 91, p. 532-540, 2003.

CALLAWAY, M. B. A compendium of crop varietal tolerance to weeds. Am. J. Altern. Agric., v. 7, p. 169-180, 1992.

COSTA, J. A.; MARCHEZAN, E. Características dos estádios de desenvolvimento da soja. Campinas: Fundação Cargill, 1982. $30 \mathrm{p}$.

CROTSER, M. P.; WITT, W. W. Effect of Glycine max canopy characteristics, G. max interference, and weed-free period on Solanum ptycanthum growth. Weed Sci., v. 48, p. 20-26, 2000.

DIAS FILHO, M. B. Growth and biomass allocation of the $\mathrm{C}_{4}$ grasses Brachiaria brizantha and $B$. humidicola under shade. Pesq. Agropec. Bras., v. 35, p. 2335-2341, 2000.

FALIK, O. et al. Self/non-self discrimination in roots. J. Ecol., v. 91, p. 525-531, 2003.

FOFANA, B.; RAUBER, R. Weed suppression ability of upland rice under low-input conditions in West Africa. Weed Res., v. 40, p. 271-280, 2000.

GERSANI, M. et al. Tragedy of the commons as a result of root competition. J. Ecol., v. 89, p. 660-669, 2001.

GIBSON, K. D.; FOIN, T. C.; HILL, J. E. The relative importance of root and shoot competition between waterseeded rice and Echinochloa phyllopogon. Weed Res., v. 39, p. 181-190, 1999.
INSTITUTE STATISTICAL ANALYSIS SYSTEM - SAS. User's guide. 4.ed. Cary: 1989. $846 \mathrm{p}$.

JANNINK, J. L. et al. Index selection for weed suppressive ability in soybean. Crop Sci., v. 40, p. 1087-1094, 2000.

LIU, F.; STÜTZEL, H. Biomass partitioning, specific leaf area, and water use efficiency of vegetable amaranth (Amaranthus spp.) in response to drought stress. Sci. Hortic., v. 102, p. 15-27, 2004.

MAINA, G. F.; BROWN, J. S.; GERSANI, M. Intra-plant versus inter-plant root competition in beans: avoidance, resource matching or tragedy of the commons. Plant Ecol., v. 160 , p. 235-247, 2002.

MARVEL, J. N.; BEYROUTY, C. A.; GBUR, E. E. Response of soybean growth to root and canopy competition. Crop Sci., v. 32, p. 797-801, 1992.

McPHEE, C. S.; AARSSEN, L. W. The separation of aboveand below-ground competition in plants. A review and critique of methodology. Plant Ecol., v. 152, p. 119-136, 2001.

MORALES-PAYAN, J. P. et al. Above- and below-ground interference of purple and yellow nutsedge (Cyperus spp.) with tomato. Weed Sci., v. 51, p. 181-185, 2003.

RADIN, B. et al. Crescimento de cultivares de alface conduzidas em estufa e no campo. Hortic. Bras., v. 22, p. 178-181, 2004.

RADOSEVICH, S. R; HOLT, J.; GHERSA, C. Weed ecology: implications for management. 2.ed. New York: Willey, 1997. $589 \mathrm{p}$.

RAJCAN, I.; SWANTON, C. J. Understanding maize-weed competition: resource competition, light quality and the whole plant. Field Crops Res., v. 71, p. 139-150, 2001.

SEMERE, T.; FROUD-WILLIAMS, R. J. The effect of pea cultivar and water stress on root and shoot competition between vegetative plants of maize and pea. J. Appl. Ecol., v. 38 , p. $137-145,2001$.

SHIPLEY, B.; MEZIANE, D. The balanced-growth hypothesis and the allometry of leaf and root biomass allocation. Funct. Ecol., v. 16, p. 326-331, 2002.

YANOVSKY, M. J. et al. Are phytochrome-mediated effects on leaf growth, carbon partitioning and extractable sucrosephosphate synthase activity the mere consequence of stemgrowth responses in light-grown mustard? J. Exp. Bot., v. 46, p. 753-757, 1995. 